\title{
PEMODELAN PENGELOMPOKKAN PRESTASI DOSEN MENGGUNAKAN METODE FUZZY C-MEANS
}

\author{
Sri Redjeki \\ Teknik Informatika STMIK AKAKOM \\ Jl. Raya Janti No 143 Yogyakarta \\ e-mail: dzeky@akakom.ac.id
}

\begin{abstract}
ABSTRAK
Sebuah perguruan tinggi sangat membutuhkan informasi yang valid tentang proses pembelajaran yang ada. Sebuah informasi akan mempunyai nilai lebih apabila diolah menggunakan metode yang ada pada data minin. Hal ini dikarenakan data mining dapat memberikan keakuratan hasil dan dapat digunakan sebagai sarana untuk pengambilan keputusan yang cepat dan tepat terutama yang berkaitan dengan perilaku dosen dalam proses PBM. Penelitian ini akan melakukan pemodelan untuk pengelompokkan prestasi dosen menggunakan Fuzzy C-Means. Objek penelitian ini di lakukan pada salah satu perguruan tinggi swasta di Yogyakarta. Parameter input yang digunakan pada metode FCM yaitu kehadiran mengajar, penyelesaian nilai akhir dan hasil kuesioner dari mahasiswa. Inputan 3 variabel ini dinamakan variabel independen, sedangkan nilai indeks prestasi dosen (IPAD) sebagai variabel dependen. Kelompok prestasi yang ditentukan pada penelitian ini ada 3 yaitu baik, sedang dan kurang. Data yang digunakan sebanyak 59 dosen. Hasil dari penelitian menunjukkan bahwa FCM dapat digunakan untuk melakukan pemodelan prestasi dosen dimana sebagian besar dosen berada pada kategori cluster baik untuk semua variabel yang digunakan pada penelitian ini. Variabel hasil kuesioner mempunyai hasil yang signifikan terhadap IPAD dosen semester genap 2009/2010.
\end{abstract}

Kata Kunci: Fuzzy C-Means, pemodelan, prestasi dosen

\begin{abstract}
A college desperately needs valid information about the existing learning process. A piece of information will have more value when processed using existing methods in minin data. This is because data mining can provide accurate results and can be used as a means for quick and precise decision making especially related to the behavior of lecturers in the learning process. This research will do modeling for lecturer achievement classification using Fuzzy C-Means. This research object is done at one of private universities in Yogyakarta. The input parameters used in the FCM method are teaching attendance, final score completion and questionnaire results from students. Input of 3 variables is called independent variable, while the value of lecturer achievement index (IPAD) as the dependent variable. Group of achievement determined in this research there are 3 that is good, medium and less. The data used are 59 lecturers. The results of the research indicate that FCM can be used to model lecturer achievement where most lecturers are in the cluster category good for all variables used in this research. The results of the questionnaire variables have a significant result to the IPAD lecturer semester of 2009/2010.
\end{abstract}

Keywords: achievement of lecturer, Fuzzy C-Means, modeling

\section{PENDAhUluan}

$\mathrm{S}$ ebuah perguruan tinggi yang baik dan berkualitas sangat ditentukan oleh proses pembelajaran yang ada didalamnya. Proses pembelajaran yang baik tergantung pada kualitas dari dosen yang ada didalam proses tersebut. Sebaik apapun kurikulum sebuah perguruan tinggi tidak akan dapat berjalan dengan baik kalau tidak mempunyai staf pengajar yang berkualitas dan mempunyai kompetensi di bidangnya. Di dunia pendidikan khususnya perguruan tinggi peran aktif seorang dosen sangatlah penting sebagai pengajar dalam proses belajar mengajar[1].

Dosen merupakan salah satu sivitas akademik yang memegang peran sangat penting bagi kemajuan suatu Perguruan Tinggi. Semakin banyak perguruan tinggi memiliki dosen-dosen yang kepakarannya terkenal, maka akan banyak mahasiswa yang termotivasi. Untuk dapat memonitor proses pembelajaran di sebuah perguruan tinggi perlu dilakukan pengelompokan dosen untuk melihat kinerja setiap semester[2]. Proses ini sangat bermanfaat karena perguruan tinggi dapat melihat kemajuan kinerja dosen secara periodik. Kegiatan evaluasi kinerja dosen merupakan rutinitas suatu perguruan tinggi dalam meningkatkan kualitas internal secara berkelanjutan [3]. Clustering merupakan salah satu metode Data Mining yang bersifat unsupervised (tidak terawasi). Terdapat beberapa jenis clustering, yaitu clustering klasik yaitu clustering yang mengelompokan objek untuk masuk ke dalam salah satu partisi atau kelompok. Jenis yang lain adalah clustering fuzzy yaitu Clustering yang tidak hanya menempatkan objek pada satu partisi saja tetapi bisa menjadi bagian atau partisi kelompok lain. Metode fuzzy clustering sangat tepat digunakan pada objek yang memiliki karakteristik pada lebih dari satu kelompok. 
Dari permasalahan diatas peneliti akan melakukan penelitian untuk melakukan clustering terhadap indeks prestasi dosen STMIK AKAKOM menggunakan metode Fuzzy C-Means (FCM). Adapun batasan penelitian ini antara lain: i) Menggunakan metode FCM untuk melakukan clustering indeks prestasi dosen (IPAD), ii) Data Indeks prestasi akan dibedakan untuk semester ganjil dan semester genap untuk periode akademik 2008/2009 dan iii) Kemiripan antar data akan diterjemahkan sebagai jarak kedekatan antar data dengan titik pusat .

\section{METODE}

Fuzzy clustering merupakan salah satu teknik untuk menentukan cluster optimal dalam suatu ruang vector yang didasarkan pada bentuk normal Eucledian untuk jarak antar vektor. Fuzzy clustering sangat berguna bagi pemodelan fuzzy terutama dalam mengidentifikasi aturan-aturan fuzzy. FCM dikenal juga sebagai fuzzy ISODATA yang merupakan salah satu metode clustering jenis Hard K-Means [4].

FCM adalah teknik unutk melakukan cluster data yang mana keberadaan tiap-tiap titik data dalam suatu cluster ditentukan oleh derajat keanggotaan yang berbeda antara 0 hingga 1. Teknik FCM ditemukan oleh Jim Bezdek pada tahun 1981. Output dari FCM bukan merupakan fuzzy inference system, namun merupakan deretan pusat cluster dan beberapa derajat keanggotaan untuk tiap-tiap titik data. Konsep dasar FCM awalnya yaitu menentukan pusat cluster yang akan menandai lokasi rata-rata untuk tiap cluster [5][6].

Dasar algoritma FCM secara lengkap diberikan sebagai berikut [7][8] :

1. Tentukan :

a. Input data yang akan dicluster $\mathrm{X}$, berupa matrik berukuran $\mathrm{n} \times \mathrm{m}(\mathrm{n}=$ jumlah sampel data, $\mathrm{m}=$ atribut setaip data). $X_{i j}=$ data sample ke $-\mathrm{I}(\mathrm{i}=1,2, \ldots, \mathrm{n})$ dan atribut ke-j $(\mathrm{j}=1,2, \ldots, \mathrm{m})$.

b. Jumlah cluster yang akan dibentuk $(C \geq 2)$

c. Pangkat (pembobot $\mathrm{w}>1$ )

d. Maksimum iterasi

e. Kriteria penghentian ( $\varepsilon=$ nilai positif yang sangat kecil)

2. Bentuk matriks partisi awal U (derajat keanggotaan dalam cluster); matriks partisi awal biasanya dibuat secara acak

$$
U=\left[\begin{array}{cccc}
\mu_{11}\left(x_{1}\right) & \mu_{12}\left(x_{2}\right) & \ldots & \mu_{1 n}\left(x_{n}\right) \\
\mu_{21}\left(x_{1}\right) & \mu_{22}\left(x_{2}\right) & \ldots & \mu_{2 n}\left(x_{n}\right) \\
\ldots & & & \\
\mu_{c 1}\left(x_{1}\right) & \mu_{c 2}\left(x_{2}\right) & \ldots & \mu_{c n}\left(x_{n}\right)
\end{array}\right]
$$

3. Hitung pusat cluster $\mathrm{V}$ untuk setiap cluster

$$
V=\frac{\sum_{k=1}^{n}\left(\mu_{i k}\right)^{w} \bullet x_{k j}}{\sum_{k=1}^{n}\left(\mu_{i k}\right)^{w}}
$$

4. Perbaiki derajat keanggotaan setiap data pada setiap cluster (perbaiki matriks partisi)

$$
\mu_{i k}=\left[\sum_{j=1}^{c}\left(\frac{d_{i k}}{d_{j k}}\right)^{2 /(w-1)}\right]^{-1}
$$

dengan :

$$
d_{i k}=d\left(x_{k}-v_{i}\right)=\left[\sum_{j=1}^{m}\left(x_{k j}-v_{i j}\right)\right]^{1 / 2}
$$

5. Tentukan kriteria penghentian iterasi, yaitu perubahan matriks partisi pada iterasi sekarang dan iterasi sebelumnya

$$
\Delta=\left\|U^{t}-U^{t-1}\right\|
$$

apabila $\Delta<\varepsilon$ maka iterasi dihentikan

Data yang digunakan dalam penelitian ini adalah data kuantitatif nilai IPAD dosen pada periode semester Genap 2009/2010. Data IPAD dosen merupakan hasil dari akumulasi beberapa komponen yaitu : 1) Hasil kuesioner 
terhadap dosen dari mahasiswa, 2) Ketepatan pengumpulan nilai dosen dan 3) Presensi kehadiran dosen dalam tiap semesternya. Data IPAD ini terdiri dari 59 dosen, nilai IPAD ini merupakan nilai tiap mata kuliah yang diampu oleh masing-masing dosen sehingga nilai yang digunakan pada penelitian ini merupakan rata-rata IPAD dosen dari beberapa matakuliah yang diampu dalam semester genap T.A 2009/2010.

Sebelum data IPAD dilakukan clustering terlebih dahulu dilakukan cleaning data untuk menghilangkan data missing untuk variabel tertentu, karena data missing akan mempengaruhi hasil penentuan matrik U sehingga akan berdampak pada hasil akhir clustering FCM-nya. Penelitian ini dirancang untuk pengelompokan data menjadi 3 bagian dari 59 data IPAD yang ada. Langkah yang dilakukan pada penelitian antara lain:

\section{Identifikasi kebutuhan data}

Penelitian ini mengidentifikasi data yang dibutuhkan yaitu data nilai IPAD untuk semua dosen tetap yang mengajar pada semester Genap 2009/2010. Nilai IPAD diambil untuk masing-masing matakuliah yang diampu oleh dosen, kemudian dicari rata-rata nilai IPAD untuk tiap dosen. Data IPAD ini disimpan dalam bentuk dat dan txt dengan nama yang sama yaitu dosen.txt dan dosen.dat. Dosen.dat digunakan pada toolbox Fuzzy Clustering sedangkan dosen.txt digunakan pada command editor untuk menentukan variabel-variabel FCM.

\section{Menetapkan kuantitas data}

Kuantitas data yang digunakan dalam penelitian ini merupakan data Indeks Prestasi Akademik Dosen.

3. Memudahkan pengolahan data

Pengumpulan data yang baik akan mempermudah peneliti dalam melakukan proses selanjutnya.

\section{Prepocessing Data}

Bentuk preprocessing data yang dilakukan pada penelitian ini yaitu dengan membersihkan data yang kosong pada variabel-variabel yang digunakan. Preprocessing data ini dilakukan agar hasil analisa clustering FCM menghasilkan nilai tengah terbaik untuk masing-masing cluster.

Desain untuk penerapan algoritma FCM pada penelitian yang menggunakan MATLAB meliputi:

1. Penetuan parameter perhitungan:

a. Menentukan data yang akan dicluster berupa matrik. Data IPAD yang digunakan untuk penelitian mempunyai ukuran matrik 59 × 4. Data ini disimpan pada data dosen.txt, data akan dipanggil dari MATLAB untuk dilakukan pengolahan.

b. Menentukan jumlah cluster yang akan dibentuk yaitu 3 cluster. Hasil dari 3 cluster ini diharapkan dapat mengelompokan hasil IPAD terhadap beberapa variabel dalam rentang IPAD 1 -IPAD 2 (perlu pembinaan/kurang), IPAD 2,1 - IPAD 3 (perlu ditingkatkan/cukup) dan yang terakhir rentang IPAD 3,1 IPAD 4 (perlu dipertahankan/baik).

c. Nilai pangkat (nilai w). Pada penelitian ini menggunakan $\mathrm{w}=2$.

d. Maksimum iterasi. Akan diberikan nilai maksimum iterasi sebanyak 1000.

e. Nilai kriteria penghentian sebesar 0,00001 .

2. Buat matrik awal U (derajat keanggotaan dalam cluster). Karena jumlah data yang akan digunakan sebanyak 59 data dan jumlah cluster sebanyak 3 cluster maka matrik U yang akan dibentuk mempunyai ukuran 3 x 59 . Dalam MATLAB nilai akan kita bangkitkan setelah data dosen.txt diload, kemudian kita tentukan formula derajat keanggotaannya.

3. Hitung pusat cluster $\mathrm{V}$ untuk setiap cluster. Jumlah cluster 3 dan variabel/atribut untuk masing-masing data 4 maka ukuran pusat cluster mempunyai matrik $3 \times 4$.

4. Perbaiki derajat keanggotaan setiap data pada setiap cluster.

5. Menentukan kriteria penghenti iterasi. Apabila nilai perubahan matriks partisi < nilai 0,00001 maka iterasi akan dihentikan.

\section{HASIL}

Data IPAD dosen yang digunakan pada data penelitian sebanyak 59 dosen dengan empat variabel dimana terdapat 3 variabel independen dan 1 variabel dependen. Variabel independen yang dimaksud antara lain kuesioner penilaian terhadap dosen, kehadiran mengajar dan waktu pengumpulan nilai diakhir semester, sedangkan untuk variabel dependen pada penelitian ini adalah nilai indeks prestasi dosen (IPAD). Dari semua variabel yang digunakan pada penelitian ini data IPAD dapat dilihat pada gambar 1. 


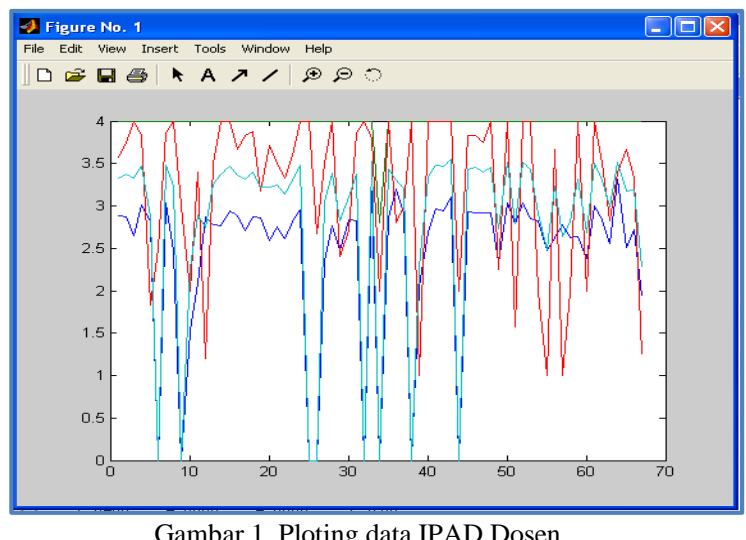

Gambar.1. Ploting data IPAD Dosen

Data yang terlihat pada gambar 1 menunjukkan bahwa beberapa dosen mempunyai kecenderungan semua variabel independen mempunyai pola yang sama, misalkan apabila seorang dosen mempunyai nilai kuesioner yang tidak bagus (turun) maka variabel yang lain akan memberikan gambaran yang tidak bagus juga (turun). Data IPAD diatas akan dilakukan pengelompokan antara hasil kuesioner terhadap nilai IPAD, penilaian terhadap nilai IPAD dan kehadiran terhadap nilai IPAD. Gambar masing-masing plot data tersebut dapat dilihat pada gambar 2, gambar 3 dan gambar 4.

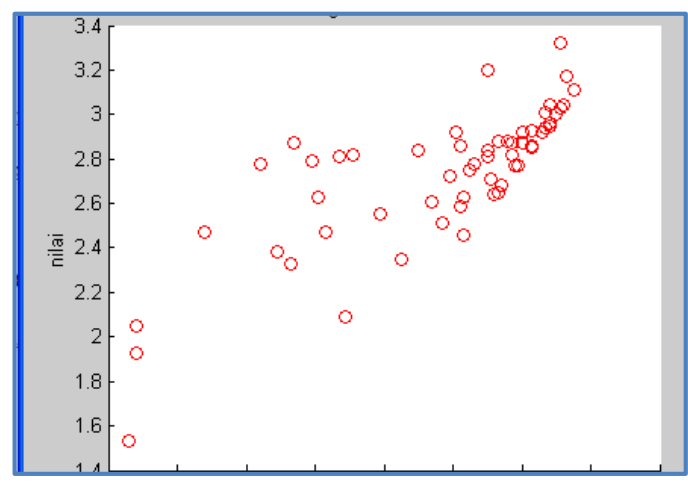

Gambar.2. Plot data IPAD vs Kehadiran Dosen

Hasil ploting data pada gambar 2 menunjukkan bahwa nilai IPAD dan kehadiran dosen tidak terlalu menyebar dan cenderung mengumpul pada area yang sama. Hal ini berbeda dengan gambar 3 yang menunjukkan ploting data antara nilai IPAD dengan proses pengumpulan nilai yang linier pada variabel pengumpulan nilai, hal ini menunjukkan bahwa semua dosen cenderung tepat waktu dalam hal pengumpulan nilai. Hasil ploting data pada gambar 4 mempunyai penyebaran yang cukup berbeda dibandingkan dengan gambar-gambar sebelumnya.

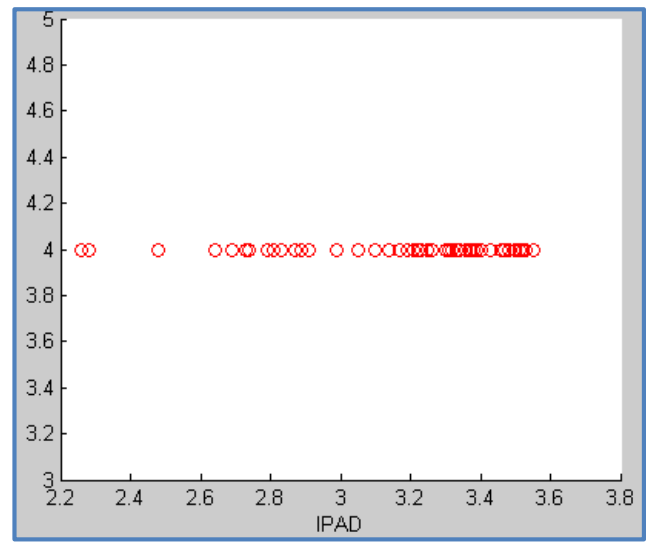

Gambar.3. Plot data IPAD vs Prosen Penilaian Dosen 


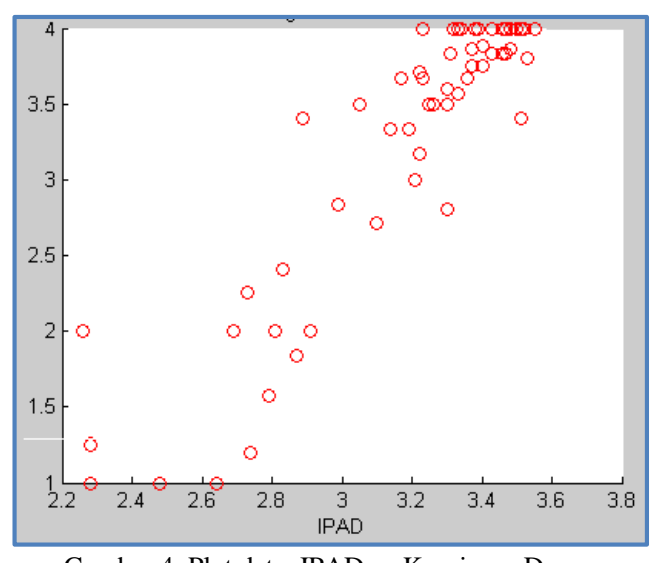

Gambar.4. Plot data IPAD vs Kuesioner Dosen

Hasil ploting data diatas akan kita lanjutkan dengan melakukan pengelompokan (clustering) FCM. Seperti pada penjelasan di atas bahwa FCM merupakan tekni clustering data yang mana keberadaan tiap-tiap titik data dalam cluster ditentukan oleh derajat keanggotaan yang berbeda antara 0 hingga 1.

\section{PEMBAHASAN}

Hasil clustering FCM pada penelitian ini dibagi menjadi tiga bagian, yaitu pertama membahas masing-masing komponen yang ada pada FCM antara lain nilai fen untuk masing-masing cluster, nilai keanggotaan $\mathrm{U}$ yang berukuran matrik $3 \times 59$, nilai pusat masing-masing cluster yang berukuran $3 \times 4$. Kedua menampilkan visualisasi hasil clustering FCM dan yang ketiga menampilkan data IPAD yang masuk pada cluster tertentu yang ditampilkan dalam tabel 1 dan 2. Hasil clustering antara variabel IPAD dan kuesioner menunjukkan bahwa dosen yang masuk pada cluster 1 dengan titik tengah $(2,63 ; 1,54)$ terdapat 11 dosen, sedangkan dosen yang masuk pada cluster 2 dengan nilai tengahnya $(3,15 ; 3,15)$ sebanyak 17 dosen sedangkan dosen yang terletak pada cluster 3 dengan nilai tengah $(3,41 ; 3,88)$ terdapat sebanyak 31 . Hasil dapat dilihat pada Tabel I.

Tabel I.

Hasil Clustering FCM (IPAD vs Kuesioner)

\begin{tabular}{|c|c|c|c|c|c|c|c|}
\hline Data & hadir & nilai & kuis & Ipad & $\begin{array}{c}\text { cluster } 1 \\
(2,63 ; 1,54)\end{array}$ & $\begin{array}{l}\text { cluster } 2 \\
(3,15 ; 3,15) \\
\end{array}$ & $\begin{array}{c}\text { cluster } \\
\mathbf{3}(\mathbf{3 , 4 1 ; 3 , 8 8})\end{array}$ \\
\hline 1 & 2.88 & 4 & 3.57 & 3.33 & & & $*$ \\
\hline 2 & 2.87 & 4 & 3.75 & 3.37 & & & $*$ \\
\hline 3 & 2.65 & 4 & 4 & 3.33 & & & * \\
\hline 4 & 3.01 & 4 & 3.83 & 3.47 & & & $*$ \\
\hline 5 & 2.81 & 4 & 1.83 & 2.87 & $*$ & & \\
\hline 6 & 3.04 & 4 & 3.86 & 3.48 & & & $*$ \\
\hline 7 & 2.46 & 4 & 4 & 3.23 & & $*$ & \\
\hline 8 & 1.53 & 4 & 2 & 2.26 & $*$ & & \\
\hline 9 & 2.09 & 4 & 3.4 & 2.89 & & $*$ & \\
\hline 10 & 2.87 & 4 & 1.2 & 2.74 & $*$ & & \\
\hline 11 & 2.78 & 4 & 3.5 & 3.26 & & $*$ & \\
\hline 12 & 2.77 & 4 & 4 & 3.38 & & & $*$ \\
\hline 13 & 2.94 & 4 & 4 & 3.47 & & & $*$ \\
\hline 14 & 2.88 & 4 & 3.67 & 3.36 & & & $*$ \\
\hline 15 & 2.71 & 4 & 3.83 & 3.31 & & & $*$ \\
\hline 16 & 2.87 & 4 & 3.88 & 3.4 & & & $*$ \\
\hline 17 & 2.86 & 4 & 3.17 & 3.22 & & $*$ & \\
\hline 18 & 2.59 & 4 & 3.71 & 3.22 & & & $*$ \\
\hline 19 & 2.75 & 4 & 3.5 & 3.25 & & $*$ & \\
\hline 20 & 2.61 & 4 & 3.33 & 3.14 & & $*$ & \\
\hline 21 & 2.81 & 4 & 3.6 & 3.3 & & & $*$ \\
\hline
\end{tabular}




\begin{tabular}{|c|c|c|c|c|c|c|c|}
\hline 22 & 2.95 & 4 & 4 & 3.48 & & & * \\
\hline 23 & 2.35 & 4 & 3.5 & 3.05 & & $*$ & \\
\hline 24 & 2.77 & 4 & 4 & 3.39 & & & * \\
\hline 25 & 2.47 & 4 & 2.4 & 2.83 & & $*$ & \\
\hline 26 & 2.84 & 4 & 2.71 & 3.1 & & $*$ & \\
\hline 27 & 2.82 & 4 & 3.86 & 3.37 & & & * \\
\hline 28 & 3.17 & 4 & 3.8 & 3.53 & & & $*$ \\
\hline 29 & 2.86 & 4 & 4 & 3.43 & & & * \\
\hline 30 & 3.2 & 4 & 2.8 & 3.3 & & $*$ & \\
\hline 31 & 2.92 & 4 & 3 & 3.21 & & $*$ & \\
\hline 32 & 2.05 & 4 & 1 & 2.28 & $*$ & & \\
\hline 33 & 2.68 & 4 & 4 & 3.34 & & & * \\
\hline 34 & 2.96 & 4 & 4 & 3.48 & & & * \\
\hline 35 & 2.94 & 4 & 4 & 3.47 & & & * \\
\hline 36 & 3.11 & 4 & 4 & 3.55 & & & * \\
\hline 37 & 2.93 & 4 & 3.83 & 3.43 & & & * \\
\hline 38 & 2.92 & 4 & 3.83 & 3.46 & & & * \\
\hline 39 & 2.92 & 4 & 3.75 & 3.4 & & & * \\
\hline 40 & 2.92 & 4 & 4 & 3.46 & & & * \\
\hline 41 & 2.33 & 4 & 2.25 & 2.73 & & $*$ & \\
\hline 42 & 3.04 & 4 & 4 & 3.52 & & & * \\
\hline 43 & 2.79 & 4 & 1.57 & 2.79 & $*$ & & \\
\hline 44 & 3.03 & 4 & 4 & 3.51 & & & * \\
\hline 45 & 2.85 & 4 & 4 & 3.43 & & & * \\
\hline 46 & 2.82 & 4 & 2 & 2.91 & $*$ & & \\
\hline 47 & 2.47 & 4 & 1 & 2.48 & $*$ & & \\
\hline 48 & 2.63 & 4 & 3.67 & 3.23 & & $*$ & \\
\hline 49 & 2.78 & 4 & 1 & 2.64 & $*$ & & \\
\hline 50 & 2.63 & 4 & 2 & 2.81 & $*$ & & \\
\hline 51 & 2.64 & 4 & 4 & 3.32 & & & * \\
\hline 52 & 2.38 & 4 & 2 & 2.69 & $*$ & & \\
\hline 53 & 3 & 4 & 4 & 3.5 & & & * \\
\hline 54 & 2.84 & 4 & 3.5 & 3.3 & & $*$ & \\
\hline 55 & 2.55 & 4 & 2.83 & 2.99 & & $*$ & \\
\hline 56 & 3.32 & 4 & 3.4 & 3.51 & & $*$ & \\
\hline 57 & 2.51 & 4 & 3.67 & 3.17 & & & * \\
\hline 58 & 2.72 & 4 & 3.33 & 3.19 & & $*$ & \\
\hline 59 & 1.73 & 2.45 & 2.1 & 2.09 & $*$ & & \\
\hline
\end{tabular}

Hasil cluster FCM yang lain antara IPAD dan kehadiran dapat dilihat pada Tabel II. Dari data tersebut dapat lihat bahwa jumlah data yang masuk pada cluster 1 dengan nilai tengah $(2,63 ; 2,49)$ mempunyai keanggotaan sebanyak 13 data, pada cluster 2 dengan nilai tengah $(3,15 ; 2,72)$ mempunyai data sebanyak 19 data, sedangkan pada cluster 3 dengan titik tengah $(3,41 ; 2,87)$ mempunyai anggota paling banyak yaitu 27 data. 
Tabel II.

Hasil Clustering FCM (IPAD vs Kehadiran)

\begin{tabular}{|c|c|c|c|c|c|c|c|}
\hline data & hadir & nilai & kuis & IPAD & $\begin{array}{c}\text { cluster } 1 \\
(2,63 ; 2,49) \\
\end{array}$ & $\begin{array}{c}\text { cluster } 2 \\
(3,15 ; 2,72) \\
\end{array}$ & $\begin{array}{c}\text { cluster } \\
\mathbf{3}(3,41 ; 2,87) \\
\end{array}$ \\
\hline 1 & 2.88 & 4 & 3.57 & 3.33 & & & $*$ \\
\hline 2 & 2.87 & 4 & 3.75 & 3.37 & & & $*$ \\
\hline 3 & 2.65 & 4 & 4 & 3.33 & & & $*$ \\
\hline 4 & 3.01 & 4 & 3.83 & 3.47 & & & $*$ \\
\hline 5 & 2.81 & 4 & 1.83 & 2.87 & & $*$ & \\
\hline 6 & 3.04 & 4 & 3.86 & 3.48 & & & $*$ \\
\hline 7 & 2.46 & 4 & 4 & 3.23 & & $*$ & \\
\hline 8 & 1.53 & 4 & 2 & 2.26 & $*$ & & \\
\hline 9 & 2.09 & 4 & 3.4 & 2.89 & $*$ & & \\
\hline 10 & 2.87 & 4 & 1.2 & 2.74 & & $*$ & \\
\hline 11 & 2.78 & 4 & 3.5 & 3.26 & & $*$ & \\
\hline 12 & 2.77 & 4 & 4 & 3.38 & & & $*$ \\
\hline 13 & 2.94 & 4 & 4 & 3.47 & & & $*$ \\
\hline 14 & 2.88 & 4 & 3.67 & 3.36 & & & $*$ \\
\hline 15 & 2.71 & 4 & 3.83 & 3.31 & & $*$ & \\
\hline 16 & 2.87 & 4 & 3.88 & 3.4 & & & $*$ \\
\hline 17 & 2.86 & 4 & 3.17 & 3.22 & & $*$ & \\
\hline 18 & 2.59 & 4 & 3.71 & 3.22 & & $*$ & \\
\hline 19 & 2.75 & 4 & 3.5 & 3.25 & & $*$ & \\
\hline 20 & 2.61 & 4 & 3.33 & 3.14 & & $*$ & \\
\hline 21 & 2.81 & 4 & 3.6 & 3.3 & & & $*$ \\
\hline 22 & 2.95 & 4 & 4 & 3.48 & & & $*$ \\
\hline 23 & 2.35 & 4 & 3.5 & 3.05 & $*$ & & \\
\hline 24 & 2.77 & 4 & 4 & 3.39 & & $*$ & \\
\hline 25 & 2.47 & 4 & 2.4 & 2.83 & $*$ & & \\
\hline 26 & 2.84 & 4 & 2.71 & 3.1 & & $*$ & \\
\hline 27 & 2.82 & 4 & 3.86 & 3.37 & & $*$ & \\
\hline 28 & 3.17 & 4 & 3.8 & 3.53 & & & $*$ \\
\hline 29 & 2.86 & 4 & 4 & 3.43 & & & $*$ \\
\hline 30 & 3.2 & 4 & 2.8 & 3.3 & & & $*$ \\
\hline 31 & 2.92 & 4 & 3 & 3.21 & & $*$ & \\
\hline 32 & 2.05 & 4 & 1 & 2.28 & $*$ & & \\
\hline 33 & 2.68 & 4 & 4 & 3.34 & & $*$ & \\
\hline 34 & 2.96 & 4 & 4 & 3.48 & & & $*$ \\
\hline 35 & 2.94 & 4 & 4 & 3.47 & & & $*$ \\
\hline 36 & 3.11 & 4 & 4 & 3.55 & & & $*$ \\
\hline 37 & 2.93 & 4 & 3.83 & 3.43 & & & $*$ \\
\hline 38 & 2.92 & 4 & 3.83 & 3.46 & & & $*$ \\
\hline 39 & 2.92 & 4 & 3.75 & 3.4 & & & $*$ \\
\hline 40 & 2.92 & 4 & 4 & 3.46 & & & $*$ \\
\hline 41 & 2.33 & 4 & 2.25 & 2.73 & $*$ & & \\
\hline 42 & 3.04 & 4 & 4 & 3.52 & & & $*$ \\
\hline 43 & 2.79 & 4 & 1.57 & 2.79 & $*$ & & \\
\hline 44 & 3.03 & 4 & 4 & 3.51 & & & $*$ \\
\hline
\end{tabular}




\begin{tabular}{cccccccc}
\hline \hline 45 & 2.85 & 4 & 4 & 3.43 & & $*$ \\
46 & 2.82 & 4 & 2 & 2.91 & & $*$ & \\
47 & 2.47 & 4 & 1 & 2.48 & $*$ & $*$ & \\
48 & 2.63 & 4 & 3.67 & 3.23 & & $*$ & \\
49 & 2.78 & 4 & 1 & 2.64 & $*$ & $*$ & $*$ \\
50 & 2.63 & 4 & 2 & 2.81 & $*$ & & $*$ \\
51 & 2.64 & 4 & 4 & 3.32 & & & $*$ \\
52 & 2.38 & 4 & 2 & 2.69 & $*$ & & \\
53 & 3 & 4 & 4 & 3.5 & & $*$ & \\
54 & 2.84 & 4 & 3.5 & 3.3 & & $*$ \\
55 & 2.55 & 4 & 2.83 & 2.99 & $*$ & & \\
56 & 3.32 & 4 & 3.4 & 3.51 & & & \\
57 & 2.51 & 4 & 3.67 & 3.17 & & $*$ \\
58 & 2.72 & 4 & 3.33 & 3.19 & & $*$ \\
59 & 1.73 & 2.45 & 2.1 & 2.09 & $*$ & & \\
\hline \hline
\end{tabular}

Melihat perbandingan dua tabel diatas dapat dilihat bahwa hasil clustering FCM menunjukkan adanya beberapa perubahan keanggotaan dosen pada 2 variabel yang dibandingkan. Belum tentu dosen yang berada pada cluster 1 untuk variabel kuesioner akan masuk juga kedalam cluster 1 untuk variabel kehadiran. Faktor perubahan keanggotaan pada masing-masing cluster yang ada dipengaruhi juga oleh titik tengah masing-masing cluster.

\section{SIMPULAN DAN SARAN}

Dari penjelasan pada bab-bab sebelumnya maka hasil penelitian ini dapat disimpulkan antara lain:

1. Variabel kuesioner merupakan variabel yang mempunyai penyebaran data cukup baik dibandingkan variabel kehadiran dan pengumpulan nilai.

2. Hasil cluster untuk variabel kuesioner dan kehadiran sebagian besar berada pada cluster 3 (cluster baik).

3. Nilai tengah untuk hasil FCM pada variable kuesioner yaitu $\mathrm{c} 1(2,6311 ; 1,5372)$, c2 $(3,1479 ; 3,1477)$ dan c3 $(3,4054 ; 3,8777)$ sedangkan untuk hasil FCM variable kehadiran mempunyai nilai tengah atau titik pusat c1 $(2,6311 ; 2,4917)$, c2 $(3,1479 ; 2,7139)$ dan c3(3,4054; 2,8695).

4. Terdapat perubahan posisi dosen pada hasil FCM untuk variabel kuesioner dan kehadiran.

5. Hasil akhir dari clustering menggunakan Fuzzy C-Means sangat dipengaruhi oleh parameter awal yang ada pada FCM.

Untuk pengembangan model penelitian selanjutnya agar menjadi lebih baik antara lain :

1. Menambahkan variabel lain dalam pengelompokkan prestasi dosen

2. Mengembangkan menjadi sistem aplikasi berbasis model softcomputing

3. Menggunakan pemodelan metode lain untuk dapat membandingkan hasil

\section{REFERENSI}

[1] Andri Wijaya, Jacqueline Henny, “Aplikasi Evaluasi Kinerja Dosen Berbasis Web Pada Sekolah Tinggi Musi”, Prosiding Semantik, ISBN 979- 260255- 0m 23 Juni 2012.

[2] Emha Taufik Lutfi, "Fuzzy C-Means Untuk Clustering Data (Studi Kasus : Data Performance Mengajar Dosen)”, Prosiding Seminar Nasional Teknologi, ISSN : 1978 -9777 Yogyakarta, 24 November 2007.

[3] Hamzah, Sunyoto, Paulus, "Sistem Pendukung Keputusan Kinerja Dosen Menggunakan Balance Scorecard “, Prosiding Semnasif, Vol I, No 5 Tahun 2010.

[4] Jiawei Han,Micheline Kamber, Data Mining : Concepts and Techniques, Morgan Kaufmann Publisher, Microsoft research,2007.

[5] Sri Kusumadewi, Hari Purnomo, Aplikasi Logika Fuzzy untuk pendukung Keputusan, Graha Ilmu, 2004

[6] Sri Kusumadewi, Analisis dan Desain Sistem Fuzzy menggunakan Toolbox Matlab, Graha Ilmu, 2002.

[7] Yan Jun, Michael dan James, Using Fuzzy Logic (Toward Intelligent System), New York, Prentice Hall.

[8] Zimmermann, Fuzzy Set Theory an Its Application, Kluwer Academic Publisher 